\title{
Gestão da Educação a Distância na universidade pública como campo de disputa: da instituição social à academia líquida
}

\author{
Management of Distance Learning in the public university as a field of dispute: \\ from social institution to fluid academy \\ Gestión de la Educación a Distancia en la universidad pública como campo de \\ disputa: de la institución social a la academia fluida
}

\section{DANIEL MILL \\ MARCELLO FERREIRA DEISE MAZZARELLA GOULART FERREIRA}

\begin{abstract}
Resumo: O texto é uma reflexão teórico-crítica sobre as mais convencionais tipologias de Gestão da Educação a Distância nas instituições públicas de ensino superior brasileiras, fomentando alternativas pela universidade como instituição social. Numa abordagem eminentemente teórica, buscou-se confrontar a visão de universidade pública como instituição social àquela de organização social, tal qual preconiza o Estado neoliberal. $\mathrm{Na}$ análise, é apresentada a migração da tipologia, da lógica de universidade como instituição social para a da academia líquida, a partir das tipologias de gestão que se tem adotado.
\end{abstract}

Palavras-chave: Educação a Distância. Gestão. Políticas Públicas. Universidade Pública.

\begin{abstract}
The text is a critical reflection on the most conventional typologies of Distance Learning Management in Brazilian public higher education institutions, discussing alternatives for the university as a social institution. In this theoretical discussion, the attempt was made to collide the ideas of the public university as a social institution and social organization, as advocated by the neoliberal State. In the analysis, it is presented the migration of the typology, from the logic of university as a social institution to that of the fluid academy, from the typologies of management that have been adopted.
\end{abstract}

Keywords: distance learning; management; public policies; public university.

Resumen: El texto es una reflexión teórico-crítica sobre las más convencionales tipologías de Gestión de la Educación a Distancia en las instituciones públicas de enseñanza superior brasileñas, fomentando alternativas por la universidad como institución social. En un enfoque eminentemente teórico, se buscó confrontar la visión de la universidad pública como institución social a la de organización 
social, tal cual preconiza el Estado neoliberal. En el análisis, se presenta la migración de la tipología, de la lógica de universidad como institución social a la de la academia líquida, a partir de las tipologías de gestión que se han adoptado.

Palabras clave: Educación a distancia. Gestión. Políticas públicas. Universidad Pública.

\section{INTRODUÇÃO}

A universidade pública brasileira vem experimentando, em diferentes níveis, manifestações da desestruturação de sua base fundamental: sua função social de produção e disseminação de saberes e a efervescência de críticas sobre as relações sociais, culturais, políticas e econômicas. Justamente por isso, a atividade universitária é social, histórica e politicamente referenciada, chancelada e legitimada. Em termos bem simples, a universidade se constituiu, desenvolveu e consolidou por e para ser um espaço autônomo de produção de saberes, críticas e valores (embora não autossuficiente e isolada da sociedade).

Todavia, para além da escassez de recursos, os gestores de universidades públicas têm vivenciado condições de operação distantes daquelas típicas de uma instituição social de fato. O gerenciamento de desafios, outrora voltados para a natureza do ensino, da pesquisa e da extensão, estão latentes nos processos administrativos e de enxugamento do sistema público de ensino. Como já denunciou Chauí (2003), sob o discurso de racionalização de recursos públicos, o Estado neoliberal induz e fomenta ações que não promovem outra consequência senão a deturpação da identidade universitária, cuja missão originária clama por ações de uma instituição social; entretanto, forçada (e não há outro termo) pela dependência das políticas públicas que lhe dão subsistência, vê-se operando como uma organização social stricto sensu.

Nesse conflituoso cenário, emerge a modalidade de Educação a Distância $(\mathrm{EaD})$ nas universidades públicas, gerida num contexto de política pública típica do Estado neoliberal e marcada por um campo de disputa entre a instituição social e o que aqui passamos a denominar academia líquida - em analogia à ideia de Modernidade Líquida (BAUMAN, 2010b; 2000b; 1999b; 2001). Isto é, a dicotomia entre uma instituição profícua na construção do bem-estar social, democrática, repleta de valores e a universidade operada para o lucro, pela disputa, breve, passageira, das metas, dos programas e ações, da agilidade, da competitividade, da obsolescência, aquela em que a composição do conhecimento pertinente e perene se perde em meio àquele que é prático e operacional, aos editais das agências de fomento, esvaindo-se, liquidamente, tão logo findando o Programa, a ação ou o interesse daquele Governo por tal ação. 
Embora sejam Programas virtuosos em muitos aspectos, interessa-nos, aqui, uma reflexão direcionada para os efeitos que essa dicotomia leva à Gestão da EaD. Entendemos que essa modalidade educacional é central para o quadro educacional brasileiro, seja pelos já recorrentes argumentos das conveniências geográficas, logísticas e pela natureza da demanda seja pela configuração que têm tomado as políticas públicas de educação, as legislações educacionais e as metas estratégicas plurianuais de educação; seja, ainda, pela expansão do poder econômico associado aos grandes grupos capitalistas que ingressaram no mercado de ensino privado da $\mathrm{EaD}$, competindo agressivamente com a EaD pública. Esses elementos, no conjunto, justificam e tornam urgente analisar criticamente e buscar elementos de qualificação da Gestão da EaD no contexto das instituições públicas de ensino superior (IPES), em níveis adequadamente estratégicos e a partir de contextos, panoramas, parâmetros e ações intimamente conectadas com as ações em curso nessas instituições, tal como evidenciado nas pesquisas e produções do campo (PRETI, 2010; LITTO; FORMIGA, 2012; MILL, 2012a; ALONSO; ROCHA, 2013; FERREIRA; MILL, 2014; FERREIRA; CARNEIRO, 2015).

Nesse sentido, passamos à reflexão teórico-crítica sobre fundamentos e condicionantes da Gestão da EaD nas Instituições Púbicas de Ensino Superior (IPES), tendo por norte: (a) o atual contexto da Educação Superior (ES) brasileira como pano de fundo para a crítica dos atuais modelos de gestão da EaD pública; (b) algumas referências clássicas sobre a universidade pública como instituição social; e (c) modelos organizacionais de IPES no Brasil; buscando, (d) a partir desses modelos de gestão da EaD, propostas de tensionamentos. Precisamente, nesta reflexão, consideramos a noção de Gestão da EaD em sentido amplo, como gestão do sistema, seja em nível universitário, seja na relação da universidade com órgãos governamentais e com a sociedade.

\section{ENSINO SUPERIOR BRASILEIRO E AS RECORRENTES TIPOLOGIAS DE GESTÃO DA EAD PÚBLICA}

Alguns dados e fatos recentes auxiliam a compreender o cenário nacional em que se tensiona a universidade pública no Brasil. Levantamentos estatísticos, fatos noticiados, ações do governo e políticas públicas têm sido efetivados e veiculados nos últimos anos e merecem atenção. Informações sobre a evolução de matrículas no ensino superior (ES), contrapostas ao decréscimo do orçamento e à ampliação da rede privada - com recursos públicos, como o Fundo de Financiamento Estudantil (FIES) e Programa Universidade para Todos (PROUNI) - além de um breve olhar sobre o recente relatório do Banco Mundial (BM) sobre a educação brasileira, colaboram com nosso argumento. 
Notícias do $2^{\circ}$ semestre de 2017 indicam redução do compromisso do poder público com o ES brasileiro, pelo corte de despesas com a educação ${ }^{1} /^{2}$, controle das verbas pelo $\mathrm{MEC}^{3}$ etc. No mesmo sentido, veículos midiáticos de diferentes correntes ideológicas e partidárias, vêm indicando e denunciando que o poder público cumpre tendência de menor prioridade à educação, de forma geral, e ao ES, de modo particular - o que anuncia um preocupante panorama prospectivo para os gestores das IPES, em que o tripé ensino-pesquisaextensão terá menos atenção do que a otimização de recursos. No documento publicado pela Andifes (2017), gestores das universidades federais denunciam a descontinuidade nas políticas de financiamento dessas instituições. São fatos que evidenciam um tensionamento nas relações de indução e fomento da educação pública brasileira, tendendo a estrangular a natureza essencial da instituição universitária, especialmente em termos da sua qualidade, pertinência e equidade.

Conforme dados da Execução Orçamentária do Governo Federal (período 1994-2016), o orçamento para custeio (efetiva manutenção) e capital (investimentos) tem decrescido nos últimos cinco anos (Figura 1). De outra perspectiva, essa redução de orçamento se contrapõe à ampliação das demandas por oferta de cursos. O próprio Plano Nacional da Educação (PNE) 2014-2024 (BRASIL, 2014) prevê em sua Meta 12 a elevação da "taxa bruta de matrícula na ES para 50\% e a taxa líquida para 33\% da população de 18 a 24 anos, assegurada a qualidade da oferta e expansão para, pelo menos, $40 \%$ das novas matrículas, no segmento público" (Observatório do PNE). Assegurar qualidade na rede pública de ES mostra-se um grande desafio e na contramão dos cortes orçamentários. Os dados do Inep/MEC de 2015 indicam um panorama quantitativo mais geral da ES atualmente (Figura 2).

$\begin{array}{ll}1 & \text { https://goo.gl/pWRzZf } \\ 2 & \text { https://goo.gl/8oZ44w } \\ 3 & \text { https://goo.gl/n9ruwk }\end{array}$


Figura 1 - Evolução dos orçamentos (custeio e capital) das universidades federais, conforme a Execução Orçamentária do Governo Federal (período 1994-2016). Fonte: ANDIFES (2017, p. 10).
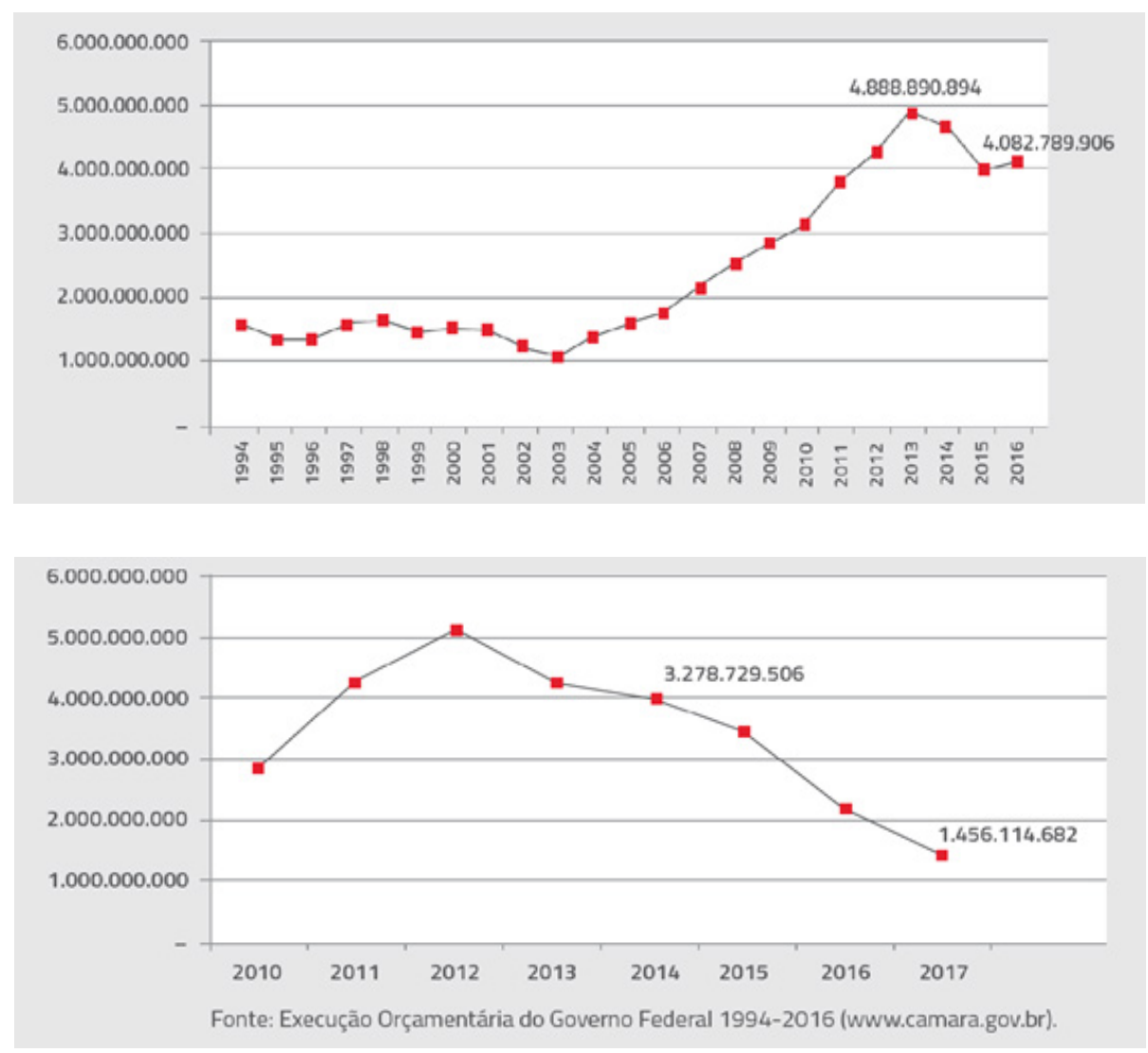
Figura 2 - Estatísticas gerais da ES, por categoria administrativa - Brasil 2015. Fonte: Censo 2016 - MEC/INEP - destaque nosso.

\begin{tabular}{|c|c|c|c|c|c|c|}
\hline \multicolumn{7}{|c|}{ Estatisticas Gerais da Educação Superior, por Categoria Administrativa - Brasil - 2015} \\
\hline \multirow{3}{*}{ Estatisticas Bdsicas } & \multicolumn{6}{|c|}{ Collegoris Alministrativa } \\
\hline & \multirow{2}{*}{ Total Geral } & \multicolumn{4}{|c|}{ Püblica } & \multirow{2}{*}{ Privada } \\
\hline & & Total & Federal & Estadual & Municipal & \\
\hline \multicolumn{7}{|l|}{ Educação Superior - Graduação } \\
\hline Instituiçōes & 2.364 & 295 & 107 & 120 & 68 & 2.069 \\
\hline Cursos' & 33.501 & 10.769 & 6.313 & 3.709 & 747 & 22.732 \\
\hline Matriculas em cursos de graduaçâo & 8.027 .297 & 1.952 .145 & 1.214 .635 & 618.633 & 118.877 & 6.075 .152 \\
\hline $\begin{array}{l}\text { Matriculas em cursos sequenciais de formaçalo } \\
\text { especifica }\end{array}$ & 6.277 & 440 & 124 & 250 & 66 & 5.837 \\
\hline Ingressos & 2.920 .222 & 534.361 & 336.093 & 161.704 & 36.564 & 2.385 .861 \\
\hline Concluintes & 1.150 .067 & 239.896 & 134.447 & 86.770 & 18.679 & 910.171 \\
\hline \multicolumn{7}{|l|}{ Educaçāo Superior - Pós-Graduaçāo Scricto Sensu } \\
\hline Matriculas & 325.230 & 269.395 & 184.041 & 83.856 & 1.498 & 55.835 \\
\hline \multicolumn{7}{|l|}{ EDUCAÇÃO SUPERIOR - TOTAL } \\
\hline Matricula Total & 8.358 .804 & 2.221 .980 & 1.398 .800 & 702.739 & 120.441 & 6.136 .824 \\
\hline Funçlo Docente em Exercicio 23 & 388.004 & 165.722 & 105.558 & 52.575 & 7.589 & 222.282 \\
\hline Docente em Exercicio 24 & 354.499 & 163.510 & 104.787 & 51.281 & 7.442 & 190.989 \\
\hline \multicolumn{7}{|l|}{ 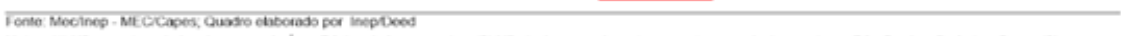 } \\
\hline \multicolumn{7}{|c|}{ 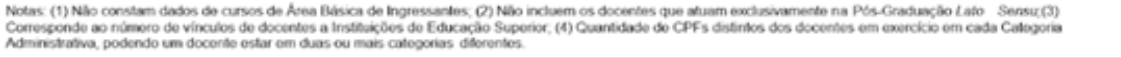 } \\
\hline
\end{tabular}

Observa-se que as IES públicas são responsáveis, aproximadamente e apenas, por $1 / 4(26,58 \%)$ das matrículas no ES, contra quase $3 / 4$ de vagas do ensino privado - quantidades muito distantes dos anseios do atual PNE. Segundo o Censo da ES de 2016, a expansão necessária para atender à Meta 12 do PNE é de $75 \%$ da quantidade de matrícula ofertada atualmente na rede pública (Figura 3).

Figura 3 - Expansão necessária para atender à Meta 12 do PNE 20142024, conforme o Censo da ES de 2016. Fonte: Andifes (2017, p. 9).

\begin{tabular}{|l|r|r|c|}
\hline $\begin{array}{l}\text { Esferas } \\
\text { Administrativas }\end{array}$ & $\begin{array}{c}\text { Matriculas } \\
\text { em 2015 }\end{array}$ & $\begin{array}{c}\text { Matrículas } \\
\text { em 2024 }\end{array}$ & $\begin{array}{c}\text { \% de Acréscimo } \\
\text { de matrículas }\end{array}$ \\
\hline Federal & $\mathbf{1 . 2 1 4 . 6 3 5}$ & $\mathbf{2 . 1 2 8 . 6 5 6}$ & $\mathbf{7 5}$ \\
\hline Estadual & 618.633 & 1.084 .159 & 75 \\
\hline Municipal & 118.877 & 208.333 & 75 \\
\hline Privado & 6.075 .152 & 8.278 .657 & 36 \\
\hline TOTAL & 8.027 .297 & 11.699 .805 & 46 \\
\hline
\end{tabular}


Embora o mesmo Censo da ES 2016 indique progressiva evolução na quantidade de vagas ofertadas nas últimas décadas, com a redução do fomento nos últimos anos, parece improvável que a meta seja atingida. Os indicadores da própria Meta 12 do PNE apontam que "de 2012 a 2014 houve uma queda acentuada na participação da rede pública na expansão de matrículas", pois nesses três anos, "a queda foi de 36,1 pontos percentuais, passando de 41,6\% a 5,5\% em 2014", de acordo com Observatório do PNE (BRASIL, 2014) ${ }^{4}$.

$\mathrm{Na}$ contramão dessa questão, é lançado o recente documento do Banco Mundial: "Um Ajuste Justo - análise da eficiência e equidade do gasto público no Brasil". Esse relatório teve por objetivo "realizar uma análise aprofundada dos gastos do governo, identificar alternativas para reduzir o déficit fiscal a um nível sustentável e, ao mesmo tempo, consolidar os ganhos sociais alcançados nas décadas anteriores" (BANCO MUNDIAL, 2017, p.1 - grifos nossos). Entre as conclusões do referido relatório, afirma-se que "as despesas com ES são, ao mesmo tempo, ineficientes e regressivas” (Idem, p.13). Pelo documento, percebe-se esforço para convencimento de que os custos da formação pública sejam equivalentes ou menores ao da formação privada. O Relatório também recomenda explicitamente que a educação deve ser mais rentável (economia de pelo menos 0,5\% do PIB do orçamento federal), via cobrança pelo ensino em universidades públicas (ou por empréstimos públicos, como FIES e PROUNI).

Portanto, a perspectiva de fomento às IPES do país parece ser bem distinta das orientações do atual PNE e mais similares ao já mencionado panorama de cortes de gastos mencionado anteriormente. É o que chamaram de "ajuste justo" na ES brasileira - o que pode ser traduzido como incentivo velado à privatização e cobrança de mensalidades (precariżação).

Nesse discurso de ajuste ou reforma das IPES, saltam aos olhos os interesses de grandes grupos empresariais que operam no mercado da Educação (e especialmente na EaD), em grande medida com recursos públicos do FIES, PROUNI etc. Temos acompanhado o noticiário ${ }^{5}$ indicando a dimensão dos lucros de grupos como Kroton, Anhanguera e Estácio (mesmo antes da sua fusão), desvelando o seu interesse em operar com recursos públicos (mais da metade dos seus alunos são matriculados pelo Fies, inclusive na $\mathrm{EaD})^{6}$. Isso justifica ou valida o raciocínio mercadológico, já não tão velado, de que o ensino privado é melhor do que o público e gratuito (BANCO MUNDIAL, 2017).

\footnotetext{
4 Disponível em: https://goo.gl/xZGeZZ

5 Informação veiculada por diferentes meios, tais como: https://goo.gl/PYsCu8, https://goo.gl/ rBtw9W e https://goo.gl/UQxSUd. Acesso em: 27/2/2018.

6 Disponível em: https://goo.gl/e9ecX8. Acesso em: 27/2/2018.
} 
Pela Figura 4, observamos a evolução das matrículas no ES, por modalidade, com progressiva participação da $\mathrm{EaD}$ nas matrículas $(18,6 \% \mathrm{em}$ 2016). Contudo, a Tabela 1 indica que das quase 1,5 milhão de matrículas na EaD em 2016, a participação das IPES nas matrículas é muito pequena $(8,2 \%$ ou 122.601 vagas).

\section{Figura 4 - Evolução das matrículas na ES brasileira, por modalidade educacional (2006-2016). Fonte: Censo 2016 (MEC/INEP).}

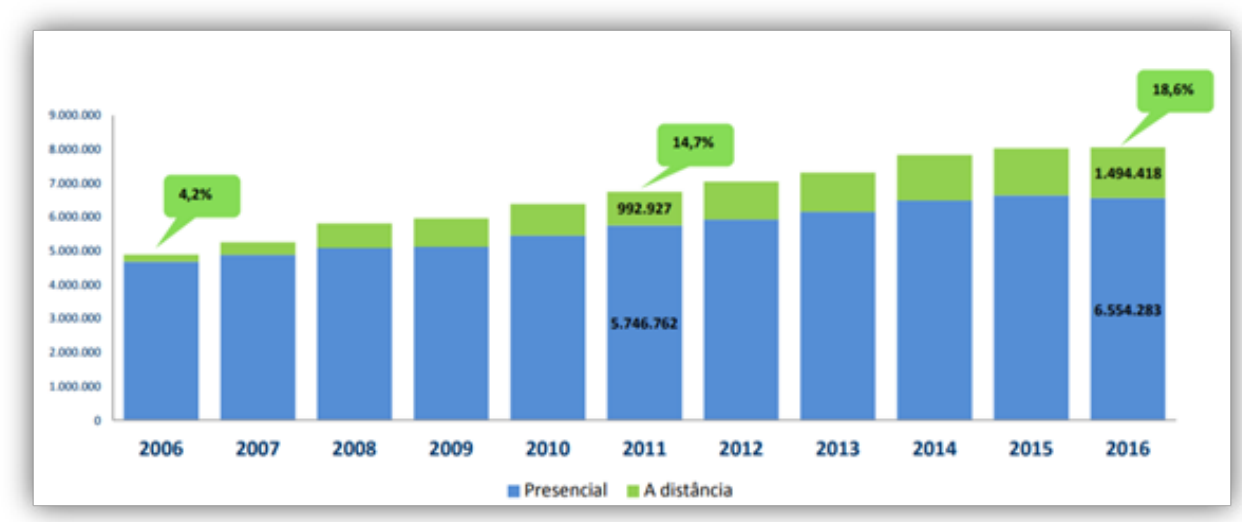

Tabela 1 - Número de matrículas na graduação, por modalidade educacional e por categoria administrativa - Brasil - 2016

\begin{tabular}{|c|c|c|c|}
\hline $\begin{array}{c}\text { Categoria } \\
\text { Ad ministrativ a }\end{array}$ & $\begin{array}{l}\text { Matrículas } \\
\text { Ed. Pres. }\end{array}$ & $\begin{array}{c}\text { Matrículas } \\
\text { E aD }\end{array}$ & Total \\
\hline Pública & $1.867 .477(23,20 \%)$ & $122.601(1,53 \%)$ & $1.990 .078(24,73 \%)$ \\
\hline Privada & $4.686 .806(58,23 \%)$ & $1.371 .817(17,04 \%)$ & $6.058 .623(75,27 \%)$ \\
\hline Total & $6.554 .283(81,43 \%)$ & $1.494 .418(18,57 \%)$ & $8.048 .701(100 \%)$ \\
\hline \multicolumn{4}{|c|}{ Fonte: Censo 2016 - MEC/INEP (Tabela sintetizada). } \\
\hline \multicolumn{4}{|c|}{$\begin{array}{l}\text { Políticas públicas como o REUNI (Plano de Reestruturação e Expansão } \\
\text { iversidades Federais) e o Sistema UAB (Sistema Universidade Aberta do } \\
\text { contribuíram sobremaneira para a ampliação das vagas na ES nas últimas } \\
\text { s. Todavia, conforme Goulart, Silva e Ferreira (2016), essas políticas } \\
\text { s promoveram mudanças na forma como a universidade se relaciona com } \\
\text { do, pois alteraram o modo pelo qual foi concretizado o financiamento da } \\
\text { ão das vagas da ES. }\end{array}$} \\
\hline
\end{tabular}


Essas políticas [REUNI e UAB] têm em comum a adoção de um financiamento baseado em metas, que passa a coexistir com a tradicional forma de provisão orçamentária das universidades federais, cujo recurso financeiro é proveniente da Lei Orçamentária Anual (LOA), materializada no orçamento próprio da instituição. Sob esta perspectiva, as universidades federais assumem o papel de prestadoras de serviço enquanto um órgão central do Estado, o de fomentar (GOULART; SILVA; FERREIRA, 2016, p. 13).

No caso do Sistema UAB, a formação se efetivou por meio de acordos, condicionando o aporte financeiro a metas pactuadas. Esse Sistema foi organizado a partir do ideal de formação em rede, em que as entidades públicas assumiriam as funções de: a) planejamento, fomento e avaliação (CAPES); b) desenvolvimento das ofertas dos programas e cursos de ES (instituições públicas); e c) constituição e manutenção dos polos de apoio presencial (Estados e Municípios). Em conjunto, essas estruturas viabilizam os cursos de nível superior a distância, que são implementados a partir da promulgação de editais pela Diretoria de Educação a Distância (DED) da CAPES (Idem, p. 18).

A relação entre as IPES e o Sistema UAB segue um modelo extremamente indutivo, acentuadamente financeirista e programático, baseado na lógica do edital, recebimento de recursos, prestação de serviços (oferta de cursos), prestação de contas, habilitação para participação em novo edital e reingresso nesse ciclo. Academicamente, é um modelo que prioriza: mediação pedagógica, uso de polos de apoio presencial, ambientes virtuais de aprendizagem, objetos de aprendizagem, materiais didáticos virtuais ou impressos, tutorias e distintas formas de docência - a polidocência, tal qual definida por Mill (2012b; 2014). Essas práticas e modelos, queiramos ou não, em maior ou menor medida, foram historicamente incorporadas, modificadas, acentuadas ou editadas a partir da matriz de fomento pactuada com a agência financiadora.

No contexto das IPES, a incorporação do Sistema UAB transformou o cenário institucional em favorável à oferta de cursos a distância, proporcionando aumento significativo de vagas na EaD demandando ampliação da estrutura institucional (MILL, 2012a; 2016). Todavia, por se basear na promulgação de editais de gerência da DED-CAPES, o modo de organização da UAB promoveu mudanças significativas na gestão administrativo-acadêmica da EaD nas IPES. Pelos editais, são oferecidas contrapartidas financeiras para contratação de pessoal e para custeio das atividades acadêmicas, induzindo as IPES a ofertarem cursos a distância, mas controlando aspectos estratégicos: áreas do conhecimento preferenciais, público-alvo de interesse, regiões geográficas prioritárias, quantitativos de vagas etc. Para Goulart, Silva e Ferreira (2016), esse modelo de financiamento contratual configura-se estratégia do governo para expansão das 
vagas, induzindo as IPES a compor um ambiente de dependência de recursos (orçamentários e de pessoal), marcada pela ausência de aportes orçamentários regulares e diretos à universidade para as ações de EaD. Por consequência, com o contrato, a IPES se submete

\begin{abstract}
Ao controle e ao acompanhamento da DED/CAPES, ao seu poder normativo, às determinações do contrato e aos seus instrumentos administrativos de avaliação de desempenho (relatórios de cumprimento de objeto, vistorias in loco) que implicam o aumento ou a redução dos sucessivos aportes de recursos conforme o desempenho auferido, a exemplo da quantidade de alunos formados (GOULART; SILVA; FERREIRA, 2016, p. 13).
\end{abstract}

Esse processo de financiamento, configurado em fomento por subordinação e dependência, implicou a organização da EaD de modo a ferir princípios institucionais, como a autonomia universitária e a liberdade pedagógicoadministrativa, tanto na relação entre a IES e o governo quanto internamente, na forma de gerenciamento do projeto dentro da instituição. Isto é, observa-se que, embora o Sistema UAB tenha contribuído para a consolidação da EaD nas IPES - marcando os anos dourados da modalidade, como argumentou Mill (2016) - ele também fomentou e induziu a institucionalização da modalidade nas IPES de modo inadequado, senão perverso.

Enfim, o Sistema UAB, como política pública, contribuiu para a consolidação e qualificação dos sistemas de EaD nas IES integrantes - por meio do desenvolvimento institucional, da formação e a capacitação de pessoal e o aperfeiçoamento da crítica sobre a EaD praticada (MILL, 2012a; 2016) - mas pecou em questões como: (i) grau de fragilidade dos modelos de fomento, propiciando incertezas quanto ao nível estratégico da política (se transitória e não estruturante); e (ii) demanda (não completamente atendida) de provisão de infraestrutura (física, tecnológica e de pessoal) adequada à consolidação, à sustentabilidade e à expansão com qualidade (FERREIRA; CARNEIRO, 2015). Conforme Ferreira e Mill (2014), Ferreira e Carneiro (2015) e Ferreira e Loguercio (2016; 2017), o cenário brasileiro desafia a EaD a superar situações como:

a) estruturar, de fato, políticas de institucionalização (planejamento, organização, infraestrutura, financiamento, pessoal e serviços ao estudante);

b) consolidar a tríade ensino-pesquisa-extensão como fator de enfraquecimento do caráter racionalista técnico da formação; e

c) fortalecer a docência (em suas múltiplas configurações), combatendo todos os mecanismos político-ideológicos de precarização do trabalho docente e, por consequência, da universidade pública.

O estabelecimento de modelos (organizacionais, pedagógicos e administrativos) é fundamental à caracterização do processo de institucionalização 
da EaD nas IPES. Todavia, a expansão dos cursos e vagas EaD não foi acompanhada, no âmbito das IES públicas (e com o requerido apoio dos órgãos de fomento, regulação e avaliação), de políticas estruturantes que promovessem organicidade aos processos de gestão da $\mathrm{EaD}$, relativamente às demais atividades de ensino, pesquisa e extensão que já integravam o rol de ações daquelas instituições, a ser evidenciado mais detalhadamente nas seções seguintes.

\section{A UNIVERSIDADE PÚBLICA COMO INSTITUIÇÃO SOCIAL E ALGUNS MODELOS ORGANIZACIONAIS: APROXIMAÇÕES ÀS TIPOLOGIAS DE GESTÃO DA EAD PÚBLICA NO BRASIL}

No contexto em que a EaD pública é reconhecida como estratégica ao desenvolvimento econômico e social do País e, consequentemente, o incentivo à sua expansão é posto em ação por meio do Sistema UAB, é importante apresentar elementos organizacionais que forneçam a compreensão do modus operandi da Universidade e como ela incorpora a suposta nova modalidade. A integração da EaD nas IPES segue o ordenamento da atual conjuntura político-econômica do Brasil, marcado pela drástica e já referida redução orçamentária. Nas próximas duas seções, serão tratadas questões tangentes às pressões vividas pela universidade, legítima como instituição social, autônoma e plural.

\section{TIPOLOGIAS DE GESTÃO DAS IPES: APROXIMAÇÕES}

A Universidade é uma instituição social que se legitima por sua capacidade de criar, deter e disseminar conhecimento, que se viabiliza pelo cultivo dos valores de autonomia, pluralidade de ideias, respeito e solidariedade. Todavia, compreender a organização universitária com esses valores envolve a adoção de um complexo e vasto campo teórico das abordagens organizacionais, especialmente por se tratar de instituição pública, com as características peculiares do Estado Brasileiro. Como afirmam Hardy e Fachin (2000), a Universidade como objeto de análise possibilitou a identificação de singularidades organizacionais, que a aproximaram à descrição da burocracia profissional, vista a constatação de que o poder de decisão está na sua base operacional, à metáfora da anarquia organizada, em razão da ambiguidade organizacional e à designação de arena política, vista sob a perspectiva do poder e do conflito.

A burocracia profissional é uma configuração que apresenta aspectos da burocracia tradicional (MINTZBERG, 2012), a exemplo da hierarquia de autoridade e dos cargos, da padronização dos processos de trabalho, da legalidade, dos critérios impessoais e da divisão do trabalho. Todavia, além desses elementos, 
a IPES possui alto grau de especialização em sua base operacional, detendo grande poder de decisão e de autonomia. A padronização em especialidades, a partir do forte treinamento conferido aos profissionais do conhecimento (docentes), propicia que cada um trabalhe com relativa independência, configurando, assim, uma supervisão hierárquica branda. Ainda assim, a organização assume um funcionamento mais padronizado e controlável, com objetivos claramente definidos. Os seus integrantes são encorajados a perseguir os objetivos organizacionais pelas contrapartidas compensatórias, a exemplo de salário, prestígio, autonomia, formação etc.

$\mathrm{Na}$ burocracia profissional, sob a influência das normas, muitas das decisões se dão no âmbito do julgamento individual (sobretudo, de docentes), notadamente as relativas ao ensino e à pesquisa. Entretanto, a Universidade também se caracteriza pela coletividade ou colegialidade (HARDY; FACHIN, 2000), cujo pressuposto ideológico é a gestão democrática (MANO; MARQUES, 2012). Rothschild e Whitt (1986, apud HALL, 2004) afirmam que em uma organização democrática o controle se dá, em última instância, pela coletividade. A decisão coletiva acontece com a reunião de gestores, docentes, apoio técnico, discentes e sociedade civil "em complexos sistemas de comissões que tipificam a maioria das universidades [...] [que comumente são] descritas como colegiais, políticas, anárquicas ou racionais" (HARDY; FACHIN, 2000, p. 31).

Baldridge (1971) reconhece a colegialidade e a respectiva relação hierárquica entre as diferentes unidades colegiais. Contudo, ele deteve sua análise na interação dos grupos da Universidade com diferentes interesses, valores e percepções da realidade, que conflitam entre si e cujo processo de decisão é reflexo da negociação. Com essa perspectiva, Baldridge (1971) tipificou a universidade como uma instituição política, embora reconheça que existam muitos elementos burocráticos na sua organização. Nesse tipo de organização, o conflito e o poder são centrais na análise. Para o autor, os indivíduos agrupam-se conforme seus interesses e seus poderes, cujas fontes podem ser as mais diversas, para sobreporem suas decisões.

Nessa perspectiva, os objetivos institucionais, assim como as estratégias e as decisões, serão resultados da ação de um determinado grupo que age e detém a maior fonte de poder naquele momento (SILVA, 2004). Para outros autores (PFEFFER; SALANCIK, 1978; LEITÃO, 1990; HARDY; FACHIN, 2000), as maiores disputas que se davam pelos recursos e uma fonte de poder se relacionariam à capacidade de dispor e de alocar recursos ordinários.

A coexistência da estrutura hierárquica top-down e a profissional dos colegiados, assim como a pulverização do poder, provoca certa ambiguidade na organização universitária. Por essa razão, autores como Cohen e March (1974, apud 
HARDY; FACHIN, 2000) aproximaram a Universidade da anarquia organizada, visto que ações individuais produzem um fluxo de decisões não dirigidas e não relacionadas diretamente aos objetivos pretendidos por indivíduos específicos. A relativa desordem presente na IPES, justificada pelo não estabelecimento de uma unidade de controle é sustentada como necessária à criação e à produção do conhecimento.

As IPES brasileiras, ainda que guardem suas particularidades, apresentam estruturas homogêneas, cuja explicação assenta-se nos elementos oriundos da visão institucional. Assim, ganha ênfase a relação de influência mútua entre organizações e campos organizacionais, com suas respectivas estruturas normativas e culturais. Conforme Goulart, Vieira e Carvalho (2005), a organização não somente responde às questões simbólicas, normativas e técnicas, mas também as constroem "por meio das relações e vínculos que estabelecem no ambiente, transformando-se em instituições” (p. 20).

A instituição é 'o produto natural das pressões e necessidades sociais - um organismo adaptável e receptivo’ (SELZNICK, 1972, p. 5) e como tal, assume caráter específico, valiosa em si mesma, independentemente dos produtos ou serviços que ofereça" (GOULART; VIEIRA; CARVALHO, 2005, p. 31).

A universidade pública brasileira, social que é, representa um bem em si própria, legitimada para a produção e disseminação do conhecimento comprometido com a verdade e com o bem social, livre de interferências políticas e econômicas. Essas crenças a movem e a fazem assumir e compartilhar valores como autonomia, pluralismo de ideias, universalismo das descobertas, solidariedade aos injustiçados e discriminados, ética e excelência. Essa simbologia a faz desenvolver uma estrutura que se aproxima das tipologias burocracia profissional, arena política, anárquica organizada e colegial.

Porém, a pressão do ambiente político-institucional para afirmar um cenário de expansão do quantitativo de vagas na ES choca-se com essa estrutura institucional, visto que impõe à universidade um ambiente técnico racional de ampliação de vagas que privilegia a formação de quadros técnicos e a eficiência numérica das matrículas. Contudo, o ambiente institucional preconiza a expansão qualificada de vagas qualificada a partir do interesse social por uma nova área de conhecimento, cujo movimento seja natural da instituição. Não se questiona a legitimidade social da expansão de vagas, obviamente, mas do vetor dessa expansão, que direciona as regiões geográficas, as áreas do conhecimento, os ritmos de atendimento, dentre outras características da oferta - que tem sido altamente induzida pela lógica de fomento, com apequenamento das decisões autônomas das instituições, cada vez mais dependentes dos recursos financeiros. 
Dessa dependência, surge uma configuração, uma tipologia que descrevemos a seguir: um breve retrato da incorporação da EaD nas IPES brasileiras.

\section{UM BREVE RETRATO DAS TIPOLOGIAS DE GESTÃO DA EAD NAS IPES BRASILEIRAS}

Analisar a incorporação da modalidade de EaD nas IPES parece simples do ponto de vista histórico, ao menos para quem, como nós, vivenciou esse processo em desenvolvimento. Parece simples, efatiza-se, porque ainda é um processo muito recente e, também, por ter certa padronização, especialmente após adesão das IPES ao Sistema UAB. Poucas experiências de graduação em $\mathrm{EaD}$ foram desenvolvidas nas IPES antes de 2005, quando foi criada a UAB. Por isso, em grande medida, foi o Sistema UAB que fomentou a incorporação da EaD pelas IPES. Essa aparente simplicidade oculta um processo bem complexo, seja do ponto de vista da modalidade, da instituição ou do próprio Sistema UAB. Sobretudo do ponto de vista da gestão da EaD, é necessário considerar alguns aspectos na análise.

Como principal ponto, é importante considerar que a $\mathrm{EaD}$ é uma modalidade educacional e, por isso, ela - assim como modalidades de educação especial, educação de jovens e adultos etc. - não deveria alterar a noção mais ampla de Educação. Pela educação presencial ou a distância, o ensino-aprendizagem envolve os mesmos elementos e princípios: estudantes/aprendizagem, docentes/ ensino, conteúdos, materiais didáticos, produção e disseminação de conhecimento, infraestrutura, gestão etc. Vista dessa forma, dentro da IPES, o desenvolvimento de um curso deveria considerar a natureza da formação humana e não o modo como foi veiculada - de onde se conclui que a IPES deveria fomentar as modalidades em seu seio de modo invisível; isto é, de maneira institucionalizada. Dessa forma, todo o tratamento a qualquer das modalidades decorreria em prol de maior valorização de suas riquezas ou limitações, antes do tratamento diferenciado decorrente de questões técnicas específicas da modalidade.

Enfim, é aspecto mais amplo, que podemos denominar institucionalização da EaD. Algo essencial, que afeta vários outros elementos tangentes à Gestão da $\mathrm{EaD}$ no processo de incorporação da modalidade. Questões técnicas, financeiras, pedagógicas, logísticas e outras mostram-se, apenas, como decorrências da fase (mais adiantada ou não) do processo de institucionalização da EaD em certa IPES (FERREIRA; MILL, 2014; FERREIRA; CARNEIRO, 2015).

Mas, de que modo a EaD foi (e/ou está sendo) incorporada na maioria das IPES? Especialmente após a adesão ao Sistema UAB, as IPES se organizaram 
para a oferta de novos cursos, de nova forma, com novos lugares e momentos de ensino-aprendizagem. Pelas discussões tecidas anteriormente, a institucionalização da EaD nas IPES não tem sido muito positiva, sobretudo em função do modelo induzido pela forma do fomento e também pela inexperiência das IPES com a modalidade (inclusive em termos da Gestão da $\mathrm{EaD}$ ).

Como já mencionamos, o financiamento pelo Sistema UAB se dá por meio de editais, implementados pela descentralização de recursos para execução de planos de ações. Não como é financiada a educação presencial, os recursos financeiros da $\mathrm{EaD}$ dependem da execução (ou não) das ações previstas, o que afeta drasticamente a noção de instituição universitária e o processo pilar de institucionalização da EaD. No custeio regular da IPES, o financiamento segue o custo-aluno, realizado anualmente pelo Governo Federal, de modo perene e diretamente pelo orçamento matricial das instituições. O cálculo para definição dos valores leva em conta vários fatores (tipo de curso, número de alunos, condições de oferta, particularidades da instituição etc.) ${ }^{7}$. Na aplicação do recurso, a IPES goza de ampla autonomia, conferida pela Constituição Federal, garantindo-lhe realizar com melhor desenvoltura as atividades de ensino-pesquisa-extensão.

Como os recursos para formação a distância nas IPES têm seguido outro ordenamento, a instituição e a $\mathrm{EaD}$ sofrem consequências diversas, a exemplo da perda da autonomia na destinação dos recursos, na organização pedagógica da formação, na garantia de perenidade na oferta dos cursos e atendimento à demanda social. Nesse cenário, registramos o seguinte retrato: adoção de procedimentos distintos, em cada IPES, para realizar a mesma formação; geração de tipologias organizacionais estranhas à própria IPES (e às outras congêneres); desenvolvimento de processos diferentes, na mesma IPES, para atendimento a estudantes de cada modalidade; organização pedagógica e curricular desarticulada de princípios norteadores institucionais; criação de infraestrutura e fluxos estranhos aos setores, normas e sujeitos da IPES, gerando desconfortos, ruídos, disputas e preconceitos entre as partes etc. Na prática, esse retrato representa um grande desafio aos gestores institucionais e da EaD, pois são cotidianamente expostos a situações anormais à condição de instituição universitária pública. Por exemplo, contratação de pessoal como celetistas ou bolsistas, duplicação de funções e ações já típicas da educação presencial, criação de normas e procedimentos em paralelo a similares da educação presencial, execução financeira de modo alternativo ao tradicionalmente estabelecido pelas orientações legais, entre outros. 
De modo geral, frente a esse turbulento processo, observamos o estabelecimento preponderante de duas tipologias de organização da $\mathrm{EaD}$ nas IPES vinculadas ao Sistema UAB:

a) tipologia que centraliza todas as atividades de $\mathrm{EaD}$ num único setor; e

b) tipologia mais descentralizada, que busca capilarizar os setores institucionais para incorporar a modalidade.

Ademais, a organização da EaD nas IPES tem algumas ações ordenadas, fomentadas ou até controladas por uma instância interna específica, especializada em $\mathrm{EaD}$, que a depender da instituição pode ser um setor de natureza técnicoadministrativa, pedagógica ou formativa, como uma unidade acadêmica ou de apoio a outras unidades. Sua nomenclatura pode variar a depender do organograma institucional, podendo ser uma secretaria $(\mathrm{SEaD})$ ou diretoria $(\mathrm{DEaD})$, um centro $(\mathrm{CEaD})$ ou núcleo $(\mathrm{NEaD})$, um instituto ou departamento de $\mathrm{EaD}$.

Vale registrar que, na prática, os gestores enfrentam desafios em qualquer dos modelos de organização da $\mathrm{EaD}$. Ambos demonstram vantagens e desvantagens, a depender do ponto de vista analisado: a curto prazo e do ponto de vista da viabilidade das ações de EaD (geralmente estranhas aos setores da universidade); por exemplo, o modelo mais centralizado agiliza decisões e processos na execução dos cursos. Todavia, é uma tipologia muito propensa a tornar-se um gueto institucional, em que se replicam as várias instâncias e que funciona à margem das ações universitárias. Nesse caso, além de aumentar a propensão ao preconceito contra a $\mathrm{EaD}$, o planejamento, a organização, a supervisão e o controle das ações previstas são geralmente realizados em paralelo às ações da gestão central da universidade e, como consequência, têm-se mostrado como uma tipologia mais dificilmente institucionalizável, quando tomada a perspectiva de IPES como instituição social.

Todavia, também a tipologia mais descentralizada tem benefícios e desvantagens, como a resistência ou (in)capacidade que os vários setores da instituição demonstram possuir quando são convocados a realizar ações da $\mathrm{EaD}$. Até certa medida, essa resistência ou dificuldade pode ser considerada normal ou natural, pois a modalidade $\mathrm{EaD}$ tem-se constituído como inovação institucional e toda inovação "incomoda" a estrutura tradicional (SOUSA, 2012). Todavia, para citar ao menos um exemplo, é positiva na perspectiva de maior possibilidade de institucionalização da EaD quando organizada de modo capilarizado e distribuído nas várias instâncias da IPES.

Em outras palavras, embora a segunda tipologia organizacional pareça menos perniciosa ao processo de incorporação da $\mathrm{EaD}$ ao seio institucional, preferimos destacar que ambas possuem grandes fragilidades, pois o terreno em que se assentam é arenoso, se não pantanoso. Afinal, a fragilidade do processo de 
institucionalização da EaD nas IPES, em ambas as tipologias organizacionais, está na agressão ao modelo de universidade como instituição social. A dependência do financiamento via editais, além da regulação, supervisão e controle por parte de órgãos centrais, gera uma situação de permanente incerteza e limitação para ações prospectivas no tocante à $\mathrm{EaD}$. Assim, tal dependência, além de afetar o princípio da autonomia universitária, induz modelos de gestão sob uma lógica organizacional distinta dos princípios da IPES como instituição social.

\section{GESTÃO DA EAD: DA ACADEMIA LÍQUIDA À RETOMADA DA NOÇÃO DE UNIVERSIDADE PÚBLICA COMO INSTITUIÇÃO SOCIAL}

Das discussões encaminhadas, sobressai o descompasso e a tensão amplamente perceptíveis entre as tipologias de gestão e financiamento, por assim dizer, regulares da universidade e aquelas aplicadas à EaD pública. Esse fenômeno reproduz e até reforça campos de disputa contrapostos pelas noções de "eficiência" nas organizações sociais e de "qualidade" nas instituições sociais. Como argumentam Goulart, Silva e Ferreira (2016), em meio a essa tensão, é necessário refletir sobre o tipo de eficiência possibilitado pela adesão ao Sistema $\mathrm{UAB}$, especialmente em função da centralização e controles da decisão na DEDCAPES, a flexibilização e a precarização do regime de trabalho dos servidores públicos, a disponibilização de serviço precário (sujeito à descontinuidade em razão da instabilidade do financiamento e dos quadros de pessoal) e a desobrigação do Estado com a manutenção da educação pública. Assim, essas características se tornam ameaçadoras quando analisadas sob a ótica da universidade pública, em que deveriam imperar valores como autonomia, excelência, pluralismo de ideias etc.

Nesse sentido, paira a ideia de que não combina o ideal de instituição social, os modelos de organização e o que virou a universidade dos "projetos" e "editais" - um argumento com respaldo em Chauí (1999), quando trata da universidade operacional, "voltada para si mesma enquanto estrutura de gestão e de arbitragem de contratos. Ou seja, a universidade está virada para dentro de si mesma, mas isso não significa um retorno a si e sim, antes, uma perda de si mesma" (Chaú, 1999, p. 220). Para a autora,

Essa universidade não forma e não cria pensamento, despoja a linguagem de sentido, densidade e mistério, destrói a curiosidade e a admiração que levam à descoberta do novo, anula toda pretensão de transformação histórica como ação consciente dos seres humanos em condições materiais determinadas (CHAUÍ, 1999, p. 222). 
É sob esse paradigma de concepção da universidade como instituição social, em caráter mais amplo, e de Gestão da EaD pública a partir dos pressupostos desta Universidade, em caráter mais particular, que se pode conceber outras tipologias viáveis, promissoras, democráticas, conectadas a princípios éticos e de igualdade e justiça social. Nessa esteira, recorremos ao pensamento de Bauman sobre a Modernidade (BAUMAN, 1989, 1999a, 1999b, 2000a, 2000b, 2000c, 2001, 2004, 2010a, 2010b, 2011), concordando com Santos e Silva (2002), na perspectiva de que o traço determinante e a finalidade mais notória da modernidade é o processo de derretimento de tudo o que a envolve. Como consequência desse traço, dois elementos se destacam: "a passagem da ética do trabalho para a estética do consumo e o surgimento de uma condição de impossibilidade de formação de comunidades reais" (SANTOS; SILVA, 2002, p. 44).

Então, destacam-se os três elementos que caracterizam a Modernidade Líquida para Bauman, aproximando-os ao que queremos definir como academia líquida - conceito aqui atribuído à tipologia de Gestão de EaD pública (e a outras políticas educacionais) que se têm estabelecido no Brasil:

1) o derretimento: caráter solúvel, breve, temporário, consumível de todas as coisas, estruturas e processos. Na configuração de Gestão da EaD pública no Brasil, sobretudo pela lógica indutivista do Sistema UAB, tomamos por "derretimento" os processos de desestruturação de lógicas e processos típicos da universidade pública, estabelecida para a produção e socialização plena de conhecimentos, promoção indissociável de ensino, pesquisa e extensão e diálogo democrático e promissor com a sociedade sobre os saberes profícuos e promissores, bem como sobre a crítica dos sistemas políticos, econômicos, sociais e culturais vigentes. Ao assumir concorrências "fechadas", reguladas por editais, fortemente matriciadas em parâmetros de fomento, a Gestão da EaD se submete ao modelo (à tipologia) do órgão de fomento e, portanto, à sua visão de ensino e a seu projeto institucional, abandonando valores clássicos e basais da universidade - em suma, derretendo-se enquanto instituição.

2) a migração de uma lógica do trabalho como processo ético, de subjetivação e valorização do indivíduo ${ }^{8}$ para uma perspectiva eminentemente da estética do consumo, de ordem capitalista, isto é, da produção e do descarte, da geração de valores e bens, para rápida reposição e geração de novas demandas. No contexto da Gestão da EaD, isso se evidencia na redução da importância da produção do conhecimento como valor, como riqueza universitária, manifestada na produção e no consumo de objetos e materiais instrucionais, no trabalho polidocente mal remunerado, majoritariamente sem vínculo estatutário, marcado

8 Na concepção antropológica dada por Marx, não por sua exterioridade, na perspectiva da exploração Capitalista. 
pela racionalidade técnica, com segregações de funções, sobreposição de tarefas etc. A sistemática da concorrência por editais, dos "cursos nacionais" (com projetos pedagógicos e materiais didáticos replicáveis), da remuneração por bolsas, das tutorias de massa, entre outras medidas de natureza economicistas, contrapõe-se ao vislumbre de grandes projetos de desenvolvimento de pesquisa e conhecimento de alto nível, com perspectiva de continuidade, com amplos investimentos em infraestrutura e formação. Tal contraposição não deixa qualquer dúvida sobre o caráter "descartável", sob a lógica do consumo antes anunciada.

3) individualização das sociedades e das práticas de promoção da competição, de tal sorte a impossibilitar a identificação de grupos homogêneos e a constituição de comunidades reais. Embora rotulada como "Sistema", a Gestão da EaD pública no Brasil é desprovida de organicidade, com imensa variação nas tipologias ou modelos de oferta dos cursos e nos formatos da proposta (plataformas educacionais, suportes e desenhos instrucionais de materiais didáticos, projetos pedagógicos, estruturas organizacionais, de gestão e administrativas). Também não há sintonia nas formas de seleção de estudantes, creditação, aproveitamento de créditos, mobilidade discente, estágios etc. De forma muito prática, o campo de investigação em EaD no Brasil, apesar de haver bem sucedidas pesquisas pontuais e focais, não é coletivamente estruturado, ao ponto de promover satisfatório e uniforme desenvolvimento de todas as IPES que atuam na modalidade, especialmente aquelas em que a oferta de cursos $\mathrm{EaD}$ é estratégica para seu projeto institucional. Essa reflexão precisa ser claramente posta, para que fique patente um fato: a lógica de Sistema não passa de um fragilizado conceito de "junção" ou "agremiação", que muito tem a desenvolver no sentido de organicidade e da geração de "comunidades reais", como pensado por Bauman.

Essas reflexões nos ajudam, portanto, antes de pensar em estratégias, processos, meios ou qualquer elemento pragmático de Gestão da EaD pública, a refletir sobre os fundamentos estruturantes de um pensamento que nos encaminhe a todos em direção a uma Gestão da EaD que seja efetivamente pública, segundo os propósitos de uma instituição social, como deve ser a universidade. Buscando identificar o projeto institucional adequado e processos de gestão apropriados, a Gestão da $\mathrm{EaD}$ pública deveria ser, antes de tudo, uma reflexão que conduza à refutação de toda tentativa de derretimento de seus princípios como instituição pública; a toda tentativa de subversão da ética do trabalho de produção qualificada do conhecimento e de apequenamento da pesquisa como princípio educativo; e a toda tentativa de obstrução do ideal de construção de comunidades reais, democráticas e solidárias que compartilhem propósitos e promovam a cooperação como forma e princípio de autonomia, desenvolvimento e liberdade. 


\section{CONSIDERAÇÕES FINAIS}

Temos aqui uma reflexão, de natureza teórico-crítica, que apresenta as mais convencionais tipologias de Gestão da EaD no contexto das IPES brasileiras, considerando a conjuntura político-financeira mais recente de fomento à educação presencial e a distância. Partindo de algumas referências sobre a universidade pública como instituição social, analisamos a tipologia de Gestão da EaD pública, argumentando e denunciando um movimento de migração da lógica de universidade como instituição social para a da academia líquida, caracterizada como organização social, tal qual preconiza o Estado neoliberal. Assim, o texto desvela, pela análise da Gestão da EaD instalada atualmente nas IPES, um movimento de transição da instituição autônoma e de valores democráticos, produtora e disseminadora de conhecimentos relevantes, para aquela que se insere na lógica solúvel do mercado, em consequência da natureza das políticas públicas em curso; isto é, denuncia-se a emergência de uma lógica de organização social, sob a qual se instalam os atuais padrões de Gestão.

Para embasar o argumento de desestruturação do pilar fundamental da universidade pública brasileira, qual seja, sua função social de produção e disseminação de saberes e efervescência de críticas sobre as relações sociais, culturais, políticas e econômicas, estabelecemos uma analogia à ideia de modernidade líquida, de Zygmunt Bauman, apresentando o termo academia líquida. $\mathrm{O}$ argumento é fundamentado na grande fragilidade do processo de incorporação da EaD nas IPES, muito agressivo à noção de universidade como instituição social. Isto é, antes de fomentar a institucionalização da $\mathrm{EaD}$ na universidade, respeitando aquela base fundamental da IPES brasileira, temos experimentado a perda da autonomia institucional, por meio da dependência do financiamento, da regulação, supervisão e do controle por parte de órgãos centrais e a latente situação de incerteza para ações prospectivas de formação a distância. Um movimento típico da universidade operacional (CHAUÍ, 1999), dos modelos de organização social ou universidade dos "projetos" e "editais".

Em vias de indicar outras tipologias, mais viáveis, promissoras, democráticas, conectadas a princípios éticos e de igualdade e justiça social, recorremos ao pensamento de Bauman sobre a Modernidade, particularmente as noções de derretimento, ética do trabalho e comunidades reais, buscando caracterizar, antes tudo, outras formas de se pensar a Gestão da EaD no âmbito público. Queremos acreditar que essas reflexões contribuam e fomentem estratégias, processos, meios ou qualquer outro elemento estruturante de uma Gestão alternativa da EaD, efetivamente pública, na direção de uma instituição 
social, como cabe à universidade em sentido amplo, independentemente da modalidade educacional, para cumprir a fundo os mais legítimos propósitos da sua riqueza institucional.

\section{REFERÊNCIAS}

ALONSO, K.; ROCHA, S. (Orgs.). Políticas públicas, tecnologias e docência. Cuiabá: Central de Texto; EdUFMT, 2013.

ANDIFES. Assoc. Nac. Dirig. Instit. Fed. de Ens. Sup. Universidades Federais: patrimônio da sociedade brasileira, 2017. Disponível em: https://goo.gl/fLs6Vm. Acesso em: 26/2/2018.

BALDRIDGE, J. Power and conflict in the university. London: Wiley, 1971.

BANCO MUNDIAL. Um ajuste justo. v.1, 2017. Disponível em: https://goo. gl/2S1NFg. Acesso em: 26/2/2018.

BAUMAN, Z. Bauman sobre Bauman. Rio de Janeiro: Zahar, 2011.

. Capitalismo parasitário. Rio de Janeiro: Zahar, 2010a.

. Legisladores e intérpretes. Rio de Janeiro: Zahar, 2010b.

. Entrevista com Zygmunt Bauman. Tempo Social, v. 16, n. 1, p. 301-325, 2004.

. Modernidade Líquida. Rio de Janeiro: Zahar, 2001

. Em busca da Política. Rio de Janeiro: Zahar, 2000a.

. Liquid modernity. Cambridge: Polity, 2000b.

. Trabajo, consumismo y nuevos pobres. Barcelona: Gedisa, 2000c.

BAUMAN, Z. Entrevista com Zygmunt Bauman. Tempo Social, v. 16, n. 1, p. 301-325, 2004.

. Globalização. Rio de Janeiro: Zahar, 1999a. 
Modernidade e ambivalência. Rio de Janeiro: Zahar, 1999b.

A liberdade. Lisboa: Estampa, 1989.

BRASIL. Plano Nacional de Educação (PNE 2014-2024). Lei ${ }^{\circ}$ 13.005, de 25/6/2014. Brasília: Câmara, 2014. 86p. Disponível em: https://goo.gl/t9rtH1. Acesso em: 26/2/2018.

CHAUÍ, M. A universidade em ruínas. In: TRINDADE, H. (Org.). Universidade em ruínas na república dos professores. Petrópolis: Vozes; Porto Alegre: CIPEDES, 1999.

CHAUÍ, M. A universidade pública sob nova perspectiva. Rev. Bras. Educ., n.24, p.5-15, 2003.

FERREIRA, M. Enunciados em Propostas de Ensino-Pesquisa-Extensão em Cursos de Física a Distância. Rev. Ensaio, v. 19, n. 1, p. 1-33, 2017.

.; CARNEIRO, T. C. J. A institucionalização da EaD no ensino superior público brasileiro. Educ. Unisinos, São Leopoldo, v. 19, n. 2, p. 228-242, maiojun. 2015.

.; LOGUERCIO, R. Análise de Competências em Projetos Pedagógicos de Licenciatura em Física a Distância. Rev. Bras. Pesq. Educ. Ciênc., v. 16, n. 2, p. 389-419, 2016.

.; LOGUERCIO, R. Enunciados em Propostas de Ensino-PesquisaExtensão em Cursos de Física a Distância: para além dos conteúdos, os discursos. Ensaio: Pesquisa em Educação em Ciências, v. 19, p. 1-33, 2017.

.; MILL, D. Institucionalização da educação a distância no Ensino Superior público brasileiro. In: REALI, A.; MILL, D. (Org.). Educação a distância e tecnologias digitais. São Carlos: EdUFSCar, 2014, p. 81-102.

GOULART, D.; SILVA, S.; M. Sistema Universidade Aberta do Brasil nas instituições federais de ensino superior. Rev. Pesq. Deb. Educ., v.6, n.2, p.11-30, 2016. 
GOULART, S.; VIERA, M.; CARVALHO, C. Universidades e Desenvolvimento Local. Porto Alegre: Sagra Luzzatto, 2005.

HALL, R. Organizações, estruturas, processos e resultados. $8^{a}$ ed. São Paulo: Prentice Hall, 2004.

HARDY, C.; FACHIN, R. Gestão estratégica na universidade brasileira. $2^{a}$ ed., Porto Alegre: EdUFRGS, 2000.

LEITÃO, S. Estrutura, cultura e desempenho organizacional na universidade. Rev. Adm. Púb. FGV, v.1, n. 24, p. 31-43, 1990.

LITTO, F; FORMIGA, M. (Org.). Educação a Distância, v. 2. São Paulo: Pearson, 2012.

MANO, M.; MARQUES, M. Novos modelos de governo na universidade pública em Portugal e competitividade. Rev. Adm. Púb., FGV, v.46, n. 3, p. 31-43, 2012.

MILL, D. Educação a Distância. Rev. Educ. Púb., v.25, n.59/2, p.432-454, 2016. . Sobre o conceito de polidocência ou sobre a natureza do processo de trabalho pedagógico na EaD. In: MILL, D.; RIBEIRO, L.; OLIVEIRA, M. (Orgs.). Polidocência na Educação a Distância. São Carlos: EdUFSCar, 2014, p. 25-42.

. A Universidade Aberta do Brasil. In: LITTO, F.; FORMIGA, M. (Orgs.). Educação a distância, v.2. São Paulo: Person, 2012a.

MILL, D. Docência virtual. Campinas: Papirus, 2012b.

MINTZBERG, H. Criando organizações eficazes. $2^{a}$ ed. $7^{a}$ reimpr. São Paulo: Atlas, 2012.

PFEFFER, J.; SALANCIK, G. The external control of organizations. New York: Harper \& Row, 1978.

PRETI, O. (org.). Educação a Distância. Cuiabá: EdUFMT, 2010. 
SANTOS, G.; SILVA, O. Conceito de "modernidade líquida". Cadernos Zygmunt Bauman, v. 3, n.5, p. 40-61, 2002.

SILVA, E. O burocrático e o político na administração universitária. 2004. 528 f. Tese (Doutorado em Educação) - Universidade do Minho, Braga, 2004.

SOUSA, J. Processo de inovação na gestão de sistemas de educação a distância. 2012. 305 f., Tese (Doutorado em Administração) - Universidade de Brasília, Brasília, 2012.

DANIEL MILL é Doutor em Educação. Professor do Departamento de Educação da Universidade Federal de São Carlos (UFSCar). Líder do Grupo de Estudos e Pesquisas sobre Inovação em Educação, Tecnologias e linguagens (Grupo Horizonte-UFSCar).E-mail: mill@ufscar.br

MARCELLO FERREIRA é Doutor em Ensino de Ciências. Professor do Instituto de Física da Universidade de Brasília (UnB). Programa de Pós-Graduação em Ensino de Física. Núcleo de Pesquisa em Ensino de Física. E-mail: marcellof@ unb.br

DEISE MAZZARELLA GOULART FERREIRA é Mestre em Administração. Administradora do Centro de Educação a Distância (CEAD) da Universidade de Brasília (UnB). E-mail: deisegoulartferreira@gmail.com

Recebido em fevereiro de 2018 Aprovado em abril de 2018 